This is the peer reviewed version of the following article:

Vázquez, J.J., Panadero, S. y Zúñiga, C. (2017). Actors, observers, and causal attributions of homelessness: Differences in attribution for the causes of homelessness among domiciled and homeless people in Madrid. American Journal of Orthopsychiatry, 87(1), 15-22,

which has been published in final form at:

https://doi.org/10.1037/ort0000130

This article may be used for non-commercial purposes in accordance with American Psychological Association and Conditions for Use of Self-Archived Versions. 
Accepted version of the article:

Vázquez, J. J., Panadero, S., \& Zúñiga, C. (2017). Actors, observers, and causal attributions of homelessness: Differences in attribution for the causes of homelessness among domiciled and homeless people in Madrid (Spain). American Journal of Orthopsychiatry, 87(1), 15-22. DOI: doi.org/10.1037/ort0000130

(C) 2016 American Psychological Association. This paper is not the copy of record and may not exactly replicate the authoritative document published in the APA journal. Please do not copy or cite without authors permission. The final article will be available, upon publication, at: $10.1037 /$ ort0000130.

\section{ACTORS, OBSERVERS AND CAUSAL ATTRIBUTIONS OF HOMELESSNESS: DIFFERENCES IN ATTRIBUTION FOR THE CAUSES OF HOMELESSNESS AMONG DOMICILED AND HOMELESS PEOPLE IN MADRID.}

\section{José Juan Vázquez}

Dept. Social Psychology

Instituto Universitaro de Investigación en Estudios Latinoamericanos (IELAT)

Universidad de Alcalá

Sonia Panadero

Dept. Clincal Psychology

Universidad Complutense de Madrid

\section{Claudia Zúñiga}

Dept. Psychology

Universidad de Chile

Corresponding author: José Juan Vázquez, Ph.D. Área de Psicología Social. Facultad de Documentación. Universidad de Alcalá. Aulario María de Guzmán. C/ San Cirilo, s/n. 28801 Alcalá de Henares. Madrid. España. E-mail: jj.vazquez@uah.es.

Funding statement: This research was supported by the "Dirección General de Investigación Científica y Técnica" of the "Ministerio de Economía y Competitvidad" of Spain, in the "VI Plan Nacional de Investigación Científica Desarrollo e Innovación Tecnológica" (Ref.

FEM2012-35053). 


\begin{abstract}
The study analyzes the differences in causal attributions of homelessness and attributions of responsibility among the members of three groups: Homeless Group, consisting of a representative sample of homeless people in Madrid, Spain $(n=188)$, Domiciled ServiceUsers Group, consisting of people at risk of homelessness $(n=164)$, and Domiciled Non ServiceUsers Group, consisting of people at no imminent risk of homelessness $(n=180)$. The Domiciled Service-Users Group and Domiciled Non Service-Users Group were matched to the Homeless Group for sex, age and nationality. The paper also analyzes homeless people's causal attributions as regards their own situation. The results show that compared to the Domiciled Non Service-Users Group, a higher percentage of members of the Homeless Group and Domiciled Service-Users Group attributed homelessness to individualistic causes, and they blamed homeless people for their situation to a greater extent. The results also show that there was no "actor-observer bias" in causal attributions for homelessness in Madrid.
\end{abstract}

Keywords: Homeless, causal attributions, poverty, social exclusion. 


\section{Introduction}

In Spain, more than a quarter of the population (27.3\%) is at risk of poverty or social exclusion (EUROSTAT, 2014), and homeless people suffer from one of the toughest situations of social difficulty. According to the Spanish National Statistics Institute, the homeless population in Spain cared for in centres amounts to 22,938 people (INE, 2012), but various nongovernmental organizations estimate that there are more than 30,000 homeless people (Plujá i Calderon, 2011). Homeless people not only live in extreme poverty, but also suffer from a high degree of family and social disengagement, with serious difficulties for reintegration into society and employment, and significant deficiencies in health (Vázquez, Panadero, Martín, \& Díaz-Pescador, 2015).

Attributions for the causes of poverty are an important issue in the processes of social inclusion-exclusion, as they reflect attitudes that can direct behaviour at both individual and institutional level (Bullock, 1999; Lott, 2002). Weiner's attribution theory (Weiner, 1986; Weiner \& Graham, 1989) bases motivation for achievement on the cognitive and emotional consequences of the causal attribution of the prior results obtained. As a result, the characteristics of the causal attribution and the psychological consequences experienced influence the individual's motivational state, therefor determine his/her future achievement behaviour. This effect may have important implications for the process of normalization of people in situations of difficulty or social exclusion since depending on the causal attributions for the individual's situation, the strategies deemed appropriate when attempting to alleviate or reverse the situation will differ (Vázquez, 2013). Likewise, attributions about the causes of poverty among the general population may influence both interactions with those suffering from poverty and/or social exclusion (Bullock, 1999; Cozzarelli, Wilkinson, \& Tagler, 2001) and the design and implementation of policies to combat poverty and the support that those policies receive (Bullock, Willians, \& Limbert, 2003).

Feagin's traditional classification of causal attributions of poverty (1972) makes a distinction between individualistic causes (which attribute responsibility to poor people for their own situation); societal causes (which make external forces responsible for people's poverty ) and fatalistic causes (which attribute poverty to factors that are beyond the control of poor individuals, and are not the responsibility of society). Despite the criticisms of this model (Lepianka, Oorschot \& Gelissen, 2009; Weiner, Osborne \& Rudolph, 2011), this approach is the most widely used and has received empirical support (Bullock et al., 2003; Feather, 1974; Furnham, 1982; Wollie, 2009; Zucker \& Weiner, 1993; Morçöl, 1997; Niemelä, 2008), and as such it has been used in this study as the basis for analysis of the attributional differences for the causes of homelessness in Madrid.

"Actor-observer bias" consists of "actors" and "observers" tending to give different explanations of the same event, in such a way that "actors" tend to focus on external or situational factors when explaining their behavior whereas "observers" tend to see others' behavior as caused by personal characteristics or dispositional factors (Jones \& Nisbett, 1971; Nisbett \& Ross, 1980).

As regards poverty, the literature reflects the tendency of "observers" to over-attribute the causes of poverty to the dispositional characteristics of the individuals in this situation, and to under-attribute the causal impact on poverty of factors that are beyond the control of poor people. The opposite effect tends to be observed among "actors" (Campbell, Carr, \& Maclachlan, 2001; Vázquez \& Panadero, 2009). In general, errors of attribution predispose towards holding poor people responsible for their poverty, rather than situations that are beyond their control (Cozzarelli et al., 2001; Feagin, 1972). 
According to Weiner, Osborne and Rudolph (2011), the main perceived causes of poverty include excessive consumption of alcohol and drugs, lack of effort and laziness, lack of skills and abilities, low wages, prejudice and discrimination, disease and physical disability, and bad luck. When homeless people attempt to account for their situation, the results of the few studies carried out suggest that they assign a particularly important role to events related to economic problems and interpersonal conflicts and the breakdown of relationships, as well as problems of physical and mental health and alcohol and drug abuse (Muñoz et al., 1999; Tessler, Rosenheck, \& Gamache, 2001, Ji, 2006; Peressini, 2007).

Various authors (Campbell et al., 2001; Feather, 1974; Furnham, 1982; Griffin \& Oheneba-Sakyi, 1993; Mickelson \& Hazlett, 2014; Vázquez \& Panadero, 2009) have pointed out that middle-class individuals and those belonging to social groups with higher incomes, higher educational levels and less likelihood of being directly affected by poverty use attributions to individualistic rather than societal causes in their causal explanations for poverty. The opposite effect is apparent among those in a situation of poverty or those faced with the likelihood of suffering from it. Poor people in the United States (Bullock, 1999, 2004; Bullock \& Limbert, 2003) and Great Britain (Furnham, 1982) have been observed as tending more towards societal causes in their attributions of poverty, while making few attributions to fatalistic causes (Bullock \& Limbert, 2003). Meanwhile, Bullock (1999) notes that poor people have a greater tendency than middle-class individuals to believe that people accessing care resources are cheating the system, and are lazy and idle. This author also suggests that people receiving welfare benefits are more likely than middle-class people to attribute poverty to structural problems and to reject political reforms aimed at making the welfare state more restrictive, but are nevertheless also more likely to consider social welfare recipients as being dishonest and lazy (Bullock, 1999).

Various studies suggest that the general population in most European countries is less likely to attribute the causes of poverty to individual factors than in the English-speaking countries (Oorschot \& Halman, 2000; Alesina \& Glaeser, 2004). In most European countries, there is a greater tendency to attribute poverty mainly to societal causes and fatalistic causes, unlike the results observed in English-speaking countries, where there is a greater tendency to consider individualistic factors as the main causes of poverty (Bullock, 1999; Feagin, 1975; Kluegel \& Smith, 1986; Niemela, 2008; Reutter et al, 2006; Shirazi \& Biel, 2005; Oorschot \& Halman, 2000). Toro (2007) points out that the population in the United States and the United Kingdom tends to show less compassion for the homeless than in Italy and Germany.

\section{Method}

The research was conducted based on data provided by individuals belonging to three different groups:

- Homeless Group (HG) ( $\mathrm{n}=188)$ : a group consisting of a representative sample of homeless people in Madrid (84.0\% men, 16.0\% women), who were all adults ( $\mathrm{M}$ age $=47.57$ years, $\mathrm{SD}=12.172$ ), who had spent the night before the interview in a shelter or other facility for homeless people, on the street or in other places not initially designed for sleeping: abandoned buildings, basements, metro stations, etc. $71.8 \%$ were Spaniards and $28.2 \%$ were foreign. The sample size of the HG was determined from the available data on the total number of homeless people in Madrid. A strategy for random sampling in the street and in all housing resources for homeless people in Madrid was designed. According to each service capacity a specific number of participants proportionately and randomly in each service was selected. The sample selection in the street was carried out randomly and 
proportionally, as well, based on the number of homeless people sleeping on the streets of Madrid.

- Domiciled Service-Users Group (DSUG) (n=164): a group consisting of a sample of people who still had housing, but needed to use services for homeless people (soup kitchens, clothing exchanges, care associations and facilities, etc.). The members of this group were at a high risk of becoming homeless, and shared care facilities with homeless people. The DSUG sample was matched to the HG on sex ( $81.1 \%$ men, $18.9 \%$ women), age ( $\mathrm{M}$ age $=$ 45.54 years, $\mathrm{SD}=10.818)$ and nationality $(62.2 \%$ Spaniards, $37.8 \%$ foreigners). The sample was obtained by a random sampling procedure in soup kitchens and facilities providing care for people at risk of being homeless.

- Domiciled Non Service-Users Group (DNSUG) ( $\mathrm{n}=180)$ : this group consisted of a sample of people who still had housing, were not using services designed for the homeless, and were not at risk of becoming homeless. The sample was gathered in Madrid using a "quota sampling" strategy, and its alignment with the HG as regards sex $(83.8 \%$ men, $16.2 \%$ women $)$, age $(\mathrm{M}$ age $=45.36$ years, $\mathrm{SD}=14.037)$ and nationality $(76.7 \%$ Spanish, $23.3 \%$ foreign) was checked.

After explaining the aims of the investigation and the treatment that would be given to the data obtained, the informed consent of the participants was requested, and those that took part were assured that their complete anonymity would be respected at all times. A structured interview instrument was used to collect information from the HG and the DSUG. The members of the DNSUG completed a self-administered questionnaire, designed in order to enable comparison with the data obtained in the HG and DSUG.

The instrument designed to gather information on causal attributions for homelessness consisted of the initial instruction "Now, we would like your opinion on the causes that usually lead homeless people into that situation. I'm going to give various reasons and I'd like to know whether or not you agree with each one" which was followed by a list of 53 statements with alternative dichotomous responses: "agree" or "disagree". The interviewees in the HG were then asked an open question to ascertain the main reasons, in their opinion, that would explain their personal situation: What are the three main reasons that explain your current situation?

\section{Results}

The percentages of agreement with the various statements concerning the possible reasons why people are homeless in the three groups are shown in Table 1:

Table 1. Agreement with various statements about the causes of homelessness among the "Homeless Group" (HG), the "Domiciled Service-Users Group" (DSUG) and the "Domiciled Non Service-Users Group" (DNSUG).

\begin{tabular}{lcccc}
\hline Causes of homelessness & HG & DSUG & DNSUG \\
& $\%(\mathrm{n})$ & $\%(\mathrm{n})$ & $\%(\mathrm{n})$ & $\chi^{2}$ \\
\hline Because of excessive alcohol consumption & $88.3 \%(159)$ & $80.4 \%(131)$ & $87.9 \%(153)$ & 5.502 \\
Because of taking the wrong decisions & $87.1 \%(148)$ & $80.6 \%(129)$ & $76.1 \%(134)$ & $6.820^{*}$ \\
Because of having lost everything they had & $85.8 \%(151)$ & $88.1 \%(141)$ & $86.9 \%(152)$ & 0.399 \\
Because of excessive drug use & $81.9 \%(149)$ & $79.1 \%(129)$ & $88.2 \%(157)$ & 5.332
\end{tabular}


Because of having got used to the situation of being homeless and doing nothing to overcome it

Because of being unable to keep their jobs

Because of living beyond their means

Because of having had problems with the family

Because of having mental health problems

Because of a lack of support from the immediate environment (family, friends, etc.)

Because of being uprooted (migration, abandonment, etc.)

Because of the meaninglessness of their life (lack of goals, objectives, hopes, etc.).

Because of problems with their partners

Because of having experienced a lot of traumatic situations

Because of gambling addiction

Because of poor distribution of wealth

Because of the economic crisis

Because of coming from broken and troubled families

Because of not being able to take responsibility

Because of a lack of knowledge about how to overcome the situation

Because of a lack of self-confidence

Because of a lack of an ability to adapt to changes

Because of an unwillingness to change their inappropriate habits and ways

Because of social rebellion, not accepting the rules

Because of low wages

Because they don't fit in with the labour market

\begin{tabular}{|c|c|c|c|}
\hline $78.5 \%$ (135) & $71.7 \%(114)$ & $63.6 \%(112)$ & $9.386^{* *}$ \\
\hline $76.6 \%$ (134) & $73.9 \%(116)$ & $41.1 \%(72)$ & $57.954 * * *$ \\
\hline $76.4 \%$ (133) & $74.8 \%(119)$ & $58.6 \%(102)$ & $16.522 * * *$ \\
\hline $76.4 \%$ (136) & $74.1 \%(120)$ & $64.8 \%(114)$ & $6.555^{*}$ \\
\hline $75.7 \%$ (134) & $67.1 \%(108)$ & $70.1 \%(124)$ & 3.185 \\
\hline $75.1 \%(133)$ & $70.6 \%(113)$ & $64.4 \%(112)$ & 4.891 \\
\hline $73.7 \%(126)$ & $74.4 \%$ (119) & $86.9 \%(152)$ & $11.188 * *$ \\
\hline $72.5 \%$ (124) & $67.7 \%(107)$ & $60.0 \%(105)$ & $6.211 *$ \\
\hline $72.4 \%$ (123) & $65.4 \%(104)$ & $65.4 \%(104)$ & $32.071 * * *$ \\
\hline $72.4 \%$ (123) & $70.0 \%(112)$ & $56.8 \%(100)$ & $10.833 * *$ \\
\hline $72.1 \%$ (119) & $67.3 \%(109)$ & $76.3 \%(135)$ & 3.392 \\
\hline $70.9 \%(122)$ & $76.4 \%(123)$ & $56.3 \%(99)$ & $16.907 * * *$ \\
\hline $70.5 \%(122)$ & $84.0 \%$ (137) & $78.7 \%(140)$ & $9.009 * *$ \\
\hline $70.5 \%(122)$ & $67.3 \%(105)$ & $66.7 \%(118)$ & 0.678 \\
\hline $69.0 \%(120)$ & $71.5 \%(113)$ & $46.2 \%(80)$ & $27.886^{* * *}$ \\
\hline $68.8 \%(119)$ & $72.8 \%(115)$ & $56.9 \%(99)$ & $10.256^{* *}$ \\
\hline $66.9 \%(113)$ & $68.2 \%(105)$ & $58.1 \%(100)$ & 4.335 \\
\hline $66.9 \%(111)$ & $60.9 \%(98)$ & $41.0 \%(71)$ & $25.218 * * *$ \\
\hline $65.9 \%(112)$ & $62.0 \%(98)$ & $41.9 \%(72)$ & $23.036 * * *$ \\
\hline $65.5 \%(112)$ & $69.9 \%$ (109) & $49.4 \%(86)$ & $16.440 * * *$ \\
\hline $65.1 \%(112)$ & $69.3 \%(113)$ & $46.0 \%(81)$ & $22.084 * * *$ \\
\hline $65.1 \%(108)$ & $62.8 \%(98)$ & $38.5 \%(67)$ & $29.774 * * *$ \\
\hline
\end{tabular}


Because of being lazy and not making enough effort

Because of the inequality of opportunity in society

Because they don't want to work

Because of fate or bad luck

Because of being very lazy, not taking responsibility for their situation and expecting other people to sort it out for them

Because of having been thrown out of their home as a child or adolescent

Because they don't know how to apply for social welfare support

Because of having been in an institution (prison, psychiatric hospital, orphanage, juvenile facility, etc.)

Because of not having access to social welfare support

Because of being unable to control their basic impulses (aggression, sexual urges, etc.)

Because they don't know how to live with other people

Because of a lack of training and advice for getting a job

Because of suffering from illness and physical problems

Because of rejection and misunderstanding by society

Because they value freedom above all else

Because of the government

Because of prejudice and discrimination in society

Because of government incompetence/inefficiency

Because they want to be homeless

Because of being born and raised in poor families

$\begin{array}{lccc}65.1 \%(110) & 68.2 \%(107) & 26.0 \%(45) & 74.841^{* * *} \\ & & & \\ 64.2 \%(106) & 70.9 \%(112) & 70.9 \%(112) & 4.256 \\ 63.9 \%(108) & 56.4 \%(88) & 35.1 \%(60) & 30.361 * * * \\ 63.5 \%(113) & 61.8 \%(97) & 61.1 \%(107) & 0.219 \\ & & & \\ 62.4 \%(108) & 60.9 \%(95) & 27.3 \%(47) & 53.468^{* * *}\end{array}$

$61.4 \%(105) \quad 61.3 \%(98) \quad 54.5 \%(96) \quad 2.186$

$60.5 \%(104) \quad 65.2 \%(105) \quad 38.9 \%(68) \quad 27.197 * * *$

$59.6 \%(102) \quad 59.9 \%(91) \quad 61.8 \%(107) \quad 0.209$

$59.3 \%(102) \quad 63.6 \%(103) \quad 45.3 \%(78) \quad 12.453 * *$

$59.0 \%(102) \quad 55.6 \%(89) \quad 30.8 \%(53) \quad 32.370 * * *$

$58.2 \%(96) \quad 56.9 \%(87) \quad 31.2 \%(54) \quad 31.171 * * *$

$58.1 \%(100) \quad 70.4 \%(114) \quad 45.7 \%(80) \quad 20.977^{* * *}$

$56.5 \%(100) \quad 40.5 \%(64) \quad 45.1 \%(78) \quad 9.242 * *$

$55.5 \%(96) \quad 46.8 \%(73) \quad 53.1 \%(93) \quad 2.630$

$54.9 \%(90) \quad 41.9 \%(65) \quad 22.4 \%(39) \quad 37.916^{* * *}$

$51.4 \%(89) \quad 56.3 \%(90) \quad 51.5 \%(87) \quad 0.606$

$51.1 \%(89) \quad 50.3 \%(80) \quad 54.0 \%(94) \quad 0.513$

$50.0 \%(80) \quad 56.8 \%(88) \quad 49.1 \%(86) \quad 2.238$

$47.1 \%(80) \quad 37.5 \%(60) \quad 17.4 \%(30) \quad 34.871 * * *$

$45.9 \%(78) \quad 59.9 \%(95) \quad 41.6 \%(74) \quad 11.000 * *$ 
Because of they did not have access to adequate education

Because homelessness is an inevitable part of modern life

Because the "homeless" life is the easiest solution to a lot of their problems

Because of the lack of access to quality health care

Because they are not very intelligent

Because it is God's will

Because it is what they deserve
$43.9 \%(75)$

$37.3 \%(62)$

$39.6 \%(63)$

$12.2 \%(21)$

$37.565 * * *$

$33.1 \%(57)$

$33.3 \%(54)$

$19.2 \%(33)$

$11.006^{* *}$

$28.2 \%(48)$

$26.5 \%(43)$

$20.1 \%(35)$

3.376

$26.5 \%(43)$

$24.7 \%(39)$

$9.2 \%(16)$

$19.082^{* * *}$

$17.0 \%(27)$

$15.1 \%(24)$

$2.3 \%(4)$

$21.347 * * *$

$12.7 \%(22)$

$* \mathrm{p} \leq .05 ; * * \mathrm{p} \leq .01 ; * * * \mathrm{p} \leq .001$

As seen in Table 1, there is some similarity in the causes of homelessness attributed by the highest percentage of respondents in all three groups (HG, DSUG, DSNUG). More than two thirds of the participants in all three groups agreed that homelessness was the result of various individualistic causes (excessive alcohol and/or drug consumption, gambling addictions, inappropriate decisions and/or loss of everything), fatalistic causes (mental health problems, being uprooted by migration or neglect, coming from problematic dysfunctional families and/or suffering from multiple traumas) and societal causes (economic crisis). In addition, in the HG and DSUG groups, two thirds of the participants also concurred with two fatalistic causes for homelessness (lack of support from the environment and/or family problems) and one societal cause (poor distribution of wealth), as well as a significant number of individualistic causes: having become accustomed to homelessness and doing nothing to overcome it, being unable to keep a job, living beyond one's means, a lack of meaning in their life, inability to take responsibility, lack of knowledge about how to overcome their situation, lack of self-confidence and/or social rebellion and rejection of the rules.

However, more than two thirds of the members of all three groups (HG, DSUG, DSNUG) disagree with two fatalistic causes for homelessness (low intelligence and divine will), one societal cause (lack of access to quality health care) and one individualistic cause (they deserve their situation). Moreover, more than two thirds of the members of the DSNUG said they disagreed with a fatalistic cause of homelessness (homelessness is an inevitable part of modern life) and a wide range of individualistic causes: homeless people are lazy, they do not try hard enough, they are very idle, they do not take responsibility for their situation, they do not control their most primal impulses, they do not know how to live with other people, they value their freedom above all else, they want to be homeless and/or they see a homeless life as the easy solution to many of their problems.

Significant differences in the percentages of agreement between the members of the three groups were observed in 36 of the 53 causes of homelessness mentioned in Table 1. Compared with the HG-DSUG group, the members of the DNSUG gave a higher percentage of attributions to two societal causes (poor distribution of wealth and/or low wages) and two fatalistic causes (homelessness is an inevitable part of modern life and/or God's will). Meanwhile, a higher percentage of the members of the HG and the DSUG than the DSNUG expressed their agreement with a fatalistic cause for homelessness (being not very intelligent) and a large number of individualistic causes: lack of knowledge about how to keep a job, living 
beyond one's means, inability to take responsibility, inability to adapt to change, unwillingness to change old habits and customs, social rebellion and rejection of the rules, lack of adjustment to the labour market, being lazy and not trying hard enough, not wanting to work, being very idle, not taking responsibility for their situation and expecting others to sort it out, not knowing how to apply for social welfare support, not controlling their primal urges, not being able to live with others, valuing freedom above all else, wanting to be homeless and/or deserving their situation.

When the members of the HG were asked for the main reasons that in their opinion explained their homelessness, there were 125 attributions to individualistic causes (grouped into 23 causes), 89 to societal causes (grouped in 9 causes) and 85 to fatalistic causes (grouped in 9 causes):

Individualistic causes (number of attributions): Because of problems with their partner (30); Because of alcohol consumption (28); Because of drug use (20); Because of taking the wrong decisions (14); Because of the meaninglessness of their lives: lack of goals, objectives, hopes, etc. (5); Because of living beyond their means (4); Because of social rebellion and rejection of the rules (3); Because of being unable to adapt to the labour market (2); Because of a lack of ability to adapt to changes (2); Because of being lazy and not trying hard enough (2); Because of a lack of self-confidence (2); Because they don't know how to keep their jobs (2); Because they value freedom above everything else (2); Because of gambling addiction (2); Because of convenience, not taking responsibility for their situation and expecting others to sort it out (1); Because of having lost everything they had (1); Because of their inability to take responsibility (1); Because they don't know how to apply for social welfare support (1); Because they don't know how to live with other people (1); Because of an unwillingness to change inappropriate habits and customs (1); Because of not wanting to work (1); Because of having got used to the situation of being homeless and doing nothing to overcome it (1); Because of a lack of training and advice for getting a job (1).

Societal causes (number of attributions): Because of being unable to get or losing a job (43); Because of a lack of support from their immediate environment (15); Because of not having proper documentation (9); Because of the economic crisis (8); Because of government incompetence/inefficiency (4); Because of the government (4); Because of low wages (3); Because of not having access to social welfare support (2); Because of the inequality of opportunity in society (1).

Fatalistic causes (number of attributions): Because of family problems (30); Because of suffering from illness and physical problems (22); Because of having mental health problems (10); Because of the death of a first-degree relative (7); Because of bad luck (5); Because of having been in an institution: prison, psychiatric hospital, orphanage, juvenile facility, etc. (4); Because it is God's will (3); Because of being uprooted (migration, abandonment...) (3); Because of having experienced traumatic situations (1).

The level of attribution of responsibility to homeless people for their situation and the level of self-attribution of responsibility for the individual's own situation are set out in Table 2 . 
Table 2. Attributions of responsibility for homelessness and their own situation among the "Homeless Group" (HG), "Domiciled Service-Users Group" (DSUG) and "Domiciled Non Service-Users Group" (DNSUG)

\begin{tabular}{lccll}
\hline & HG & DSUG & DNSUG & \multirow{2}{*}{$\%$} \\
& $\%(\mathrm{n})$ & $\%(\mathrm{n})$ & $\%(\mathrm{n})$ & $\chi^{2}$ \\
\hline Do you believe that most homeless people are responsible for their situation? & $34.692^{* * *}$ \\
Very responsible & $23.8 \%(41)$ & $13.1 \%(20)$ & $9.6 \%(17)$ & \\
Quite responsible & $48.3 \%(83)$ & $47.1 \%(72)$ & $63.3 \%(112)$ & \\
Not very responsible & $15.7 \%(27)$ & $22.2 \%(34)$ & $23.2 \%(41)$ & \\
Not responsible at all & $12.2 \%(21)$ & $17.6 \%(27)$ & $4.0 \%(7)$ & \\
\hline Do you consider yourself responsible for your current situation? & & $70.341^{* * *}$ \\
Very responsible & $43.0 \%(77)$ & $26.9 \%(43)$ & $62.6 \%(112)$ & \\
Quite responsible & $30.7 \%(55)$ & $32.5 \%(52)$ & $30.2 \%(54)$ & \\
Not very responsible & $10.6 \%(19)$ & $17.5 \%(28)$ & $7.3 \%(13)$ & \\
Not responsible at all & $15.6 \%(28)$ & $23.1 \%(37)$ & $0.0 \%(0)$ & \\
\hline
\end{tabular}

${ }^{*} \mathrm{p} \leq .05 ; * * \mathrm{p} \leq .01 ; * * \mathrm{p} \leq .001$

Table 2 shows that the closer the individuals are to being homeless, the higher percentage of people who believe that homeless people are "very responsible" for their situation. While $72.1 \%$ of the HG, $60.2 \%$ of the DSUG and $72.9 \%$ of the DNSUG considered that homeless people were "quite or very responsible" for their situation, $12 \%, 18 \%$ and $4 \%$ respectively felt they were not all responsible for it. When the respondents were asked to what extent they considered themselves responsible for their own situation (without specifying what the situation was), $73.7 \%$ of the HG, $59.4 \%$ of the DSUG and $92.8 \%$ of the DNSUG considered themselves "quite or very responsible" for their situation. Most interviewees attributed a significant degree of personal responsibility to themselves, and this was especially pronounced in the case of the DNSUG.

While $24 \%$ of the HG and $13 \%$ of the DSUG thought that homeless people were "very responsible" for their situation, a much higher percentage, $43 \%$ and $30 \%$ respectively, considered themselves "very responsible" for their own situation.

\section{Discussion}

There were significant overlaps among the respondents from all three groups (HG, DSUG and DSNUG) in the attributions for the causes that usually lead people to become homeless. These attributions mainly refer to individualistic causes (which tend to attribute responsibility for their situation to homeless people themselves) and fatalistic causes (which attribute poverty to factors that are beyond the control of poor individuals and not the responsibility of society), with few attributions to societal causes (which hold forces external to poor people responsible for poverty), despite the situation of economic and social crisis experienced by Spain at the time the study was carried out.

The homeless respondents attributed their situation mainly to economic problems, interpersonal conflicts, physical and/or mental health problems, and excessive consumption of alcohol and/or drugs. These attributions for the causes of homelessness, with a marked tendency towards explanations derived from individualistic causes, largely match those reported by the respondents from all three groups as general causes of homelessness and the causes mentioned by homeless people themselves for their situation, as noted in previous studies (Tessler et al., 2001; Ji, 2006; Muñoz et al., 1999; Tessler et al., 2007). 
Several studies have shown that in causal explanations for poverty, people who are less likely to be directly affected by poverty use more attributions to individualistic causes than to societal causes. This is the opposite effect to that found among people in poverty or facing the possibility of being affected by it (Campbell et al., 2001; Bullock, 1999; Bullock \& Limbert, 2003; Feather, 1974; Furnham, 1982; Griffin \& Oheneba-Sakyi, 1993; Mickelson \& Hazlett, 2014; Vázquez \& Panadero, 2009). However, this situation seems to be reversed when attributions for the causes of homelessness in Madrid are studied, as homeless respondents (HG) or those at risk of that situation (DSUG) attribute homelessness to individualistic causes to a greater extent than the members of the DNSUG, which consists mainly of middle-class people. In fact, the members of the DNSUG show a higher level of disagreement with attributions of homelessness to individualistic causes than the homeless themselves (HG), who when asked about the causes for their situation, also mainly use attributions to individualistic causes.

In the same vein, people who are homeless (HG) or at risk of being in that situation (DSUG) hold most homeless people responsible for their situation to a greater extent than respondents who are not at risk of becoming homeless (DNSUG). While the level of assignment of responsibility for homelessness is very high in all three groups - more than $60 \%$ of the interviewees - the closer the interviewees' personal proximity to homelessness, the higher the percentage who considered those in that situation were "very responsible" for it. Furthermore, the majority of the respondents in all three groups self-attributed a significant level personal responsibility for their situation: over $90 \%$ of the members of the DNSUG, $74 \%$ of the HG and $59 \%$ of the DSUG considered themselves responsible for their situation to some extent. The differences among the three groups may be attributed to "self-serving bias" (Miller \& Ross, 1975). The self-serving bias refers to a tendency for people to take personal responsibility for their desirable outcomes, yet externalize responsibility for their undesirable outcomes. This bias is useful for the self-esteem, since attributions of success increase the self-esteem and denial of failure protects it. Therefore, the DNSUG, composed by middle class, 63\% considered themselves very responsible for their situation and none considered themselves "not responsible at all" for their situation. On the other hand, $40 \%$ of people at risk of becoming homeless considered themselves little or not responsible of their situation. However, more than $70 \%$ of the homeless people considered themselves responsible for their situation, which may indicated that within this group the "self-serving bias" occurs in a lesser percentage, with the negative implications this may have in the self-esteem of the homeless person. While $24 \%$ of the respondents in the $\mathrm{HG}$ and $13 \%$ of the DSUG considered most homeless people very responsible for their situation, a much higher percentage $(43 \%$ of the $\mathrm{HG}$ and $27 \%$ of the DSUG) considered themselves "very responsible" for their own situation.

"Observer-actor bias" (Jones \& Nisbett, 1971; Nisbett \& Ross, 1980) appears not to occur with regard to causal attributions for homelessness in Madrid, as homeless people (HG) self-attribute a greater responsibility for their situation than that attributed by those who are not at risk of homelessness (DNSUG). People in poverty, at risk of becoming homeless and who share care services with homeless people (DSUG) make causal attributions for homelessness similar to those made by homeless people themselves (HG). Direct contact with homeless people may help explain the attributions to individualistic causes made by members of the DSUG, which could be of a self-defensive nature (Vázquez \& Panadero, 2007). The defensive attribution bias (Shaver, 1970) makes reference to the attributions made by the observer which allows them to reduce the perception of threat in a situation. However, the elevated percentage of attribution of responsibility toward the homeless people from the at risk group, could be derived from this group trying to avoid thinking they will find themselves in a homeless situation, considering that they have characteristics that differentiate them form the homeless people and that they would react in a different manner given those circumstances. 
Compared to the English-speaking countries, among the population of continental Europe there is a lesser propensity to attribute the causes of poverty to individual issues (Oorschot \& Halman, 2000; Alesina \& Glaeser, 2004) and a greater tendency to attribute it to societal and fatalistic causes (Bullock, 1999; Feagin, 1975; Kluegel \& Smith, 1986; Niemelä, 2008; Reutter et al, 2006; Shirazi \& Biel, 2005; Oorschot \& Halman, 2000). In Madrid, people at no risk of becoming homeless (DNSUG) mainly from the middle class, showed a strong disagreement with many of the attributions for homelessness to individualistic causes, and this disagreement was much higher than that shown by people in poverty (DUSG) and/or social exclusion (HG). In this respect, attributions for homelessness among the middle classes in a continental European city like Madrid appear to be consistent with those observed in other countries in continental Europe.

The tendency to attribute homelessness to individualistic causes and make homeless people responsible for their situation may adversely affect the general perception of the collective and the belief that they do not deserve support, given the greater tendency to provide assistance when problems are attributed to causes external to those suffering from them (DeJong, 1980; Zucker \& Weiner, 1993). As a result, as pointed out by various authors (Reutter et al., 2002; Bullock et al., 2003), attributions for the causes of poverty can influence the design and implementation of policies to combat poverty and the support those policies receive. In this vein, according to Toro et al. (2007), in the United States and the United Kingdom, where attributions to individualistic causes occur to the greatest extent, the population tends to show less compassion for the homeless than in Italy and Germany. Based on this criterion, the middle class (DNSUG) in Madrid would be more likely to show compassion for the homeless than those in social difficulties (DSUG) or who are homeless (HG).

However, the tendency among homeless people to attribute their own situation to individualistic causes could have some positive effects, since this may reduce the feelings of helplessness arising from an inability to control the societal and fatalistic causes. Attribution theory (Weiner, 1986; Weiner \& Graham, 1989) postulates that the characteristics of causal attribution for the previous results obtained and psychological consequences experienced influence the individual's motivational state and therefore determine his/her future achievement behaviour. Attribution to individualistic causes could therefore facilitate the activation of personal resources among the homeless that are focused on overcoming their situation, as the causal attributions made regarding a given situation are linked to the strategies considered effective in addressing it (Panadero \& Vázquez, 2008).

This study is limited to Madrid, Spain, which makes it difficult to generalize the results to other contexts. However, the data obtained may be useful in designing intervention strategies aimed at working on causal attributions of homelessness, both among the general population with the implications that this may have on the design and implementation of policies fighting against poverty and public support for them - and with homeless people themselves, encouraging attributions focused on facilitating a resolution of the situation, with the positive impact that this may have on processes of social inclusion. 


\section{References}

Alesina, A. \& Glaeser, E.L. (2004). Fighting poverty in the US and Europe: A world of difference (Vol. 26). Oxford: Oxford University Press.

Bullock, H.E. \& Limbert, W.M. (2003). Scaling the Socioeconomic Ladder: Low-Income Women's Perceptions of Class Status and Opportunity. Journal of Social Issues, 59, 693709. DOI: $10.1046 /$ j.0022-4537.2003.00085.x

Bullock, H.E. (1999). Attributions for Poverty: A comparison of middle-class and welfare recipient attitudes. Journal of Applied Social Psychology, 29, 2059-2082. DOI: $10.1111 / \mathrm{j} .1559-1816.1999 . t b 02295 . x$

Bullock, H.E., Williams, W.R., \& Limbert, W.M. (2003). Predicting support for welfare policies: The impact of attributions and beliefs about inequality. Journal of Poverty, 7, $35-56$.

Campbell, D., Carr, S. C. \& Maclachlan, M. (2001), Attributing “Third World Poverty" in Australia and Malawi: A Case of Donor Bias? Journal of Applied Social Psychology, 31, 409-430. DOI: 10.1111/j.1559-1816.2001.tb00203.x

Cozzarelli, C., Wilkinson, A.V., \& Tagler M.J. (2001) Attitudes toward the poor and attributions for poverty. Journal of Social Issues, 57, 207-27.

DeJong, W. (1980). The stigma of obesity: The consequences of naive assumptions concerning the causes of physical deviance. Journal of Health and Social Behavior, 21, 75-87.

EUROSTAT (2014). People at risk of poverty or social exclusion by age and sex. Retrieved 10/01/15 from EUROSTAT website: http://appsso.eurostat.ec.europa.eu/nui/show.do?dataset=ilc_peps01\&lang=en

Feagin, J.R. (1972). God helps those who help themselves. Psychology Today, 11, 101-129.

Feagin, J.R. (1975). Subordinating the poor: Welfare and American beliefs. NJ Prentice Hall: Upper Saddle River.

Feather, N.T. (1974). Explanations of poverty in Australian and American samples: The person, society, or fate? Australian Journal of Psychology, 26 (3), 199-216.

Furnham, A. (1982). The perception of poverty among adolescents. Journal of Adolescence, 5, 135-147.

Griffin, W.E. \& Oheneba-Sakyi (1993). Sociodemographic and political correlates of university student's causal attributions for poverty. Psychological Reports, 73 (3), 795-800.

INE (Instituto Nacional de Estadística) (2012). Encuesta a las Personas sin Hogar. Año 2012. Retrieved 15/01/15 from INE website:

http://www.ine.es/jaxi/menu.do?L=0\&type=pcaxis\&path=\%2Ft $25 \% 2 F p 454 \&$ file $=$ ineba se

Ji, E. (2006). A study of structural risk factors of homelessness in 52 metropolitan areas in the United States. International Journal of Social Work, 49(1), 107-117.

Jones, E.E. \& Nisbett, R.E. (1971). The actor and the observer: Divergent perceptions of the causes of behaviour. In E.E. Jones, D.E. Kanouse, H.H. Kelley, R.E. Nisbett, S. Valins \& B. Weiner (Eds.). Attribution: Perceiving the Causes of Behaviour. Morristown: General Learning Press.

Kluegel, J.R., \& Smith, E. R. (1986). Beliefs about inequality: Americans'views of what is and what ought to be. New York: Aldine De Gruyter.

Lepianka, D., Van Oorschot, W., \& Gelissen, J. (2009). Popular explanations of poverty: A critical discussion of empirical research. Journal of Social Policy, 38(03), 421-438. DOI: $10.1017 / \mathrm{S} 0047279409003092$

Lott, B. (2002). Cognitive and behavioral distancing from the poor. American Psychologist, 57(2), 100-110. DOI: org/10.1037/0003-066X.57.2.100 
Mickelson, K.D. \& Hazlett, E. (2014). “Why me?”: Low-Income Women's Poverty Attributions, Mental Health, and Social Class Perceptions. Sex Roles, 71 (9-10), 319-332. DOI: $10.1007 / \mathrm{s} 11199-014-0414-4$

Miller, D.T. \& Ross, M. (1975). Self-serving biases in the attribution of causality: Fact or fiction? Psychological Bulletin, 82, 213-225.

Morçöl, G. (1997). Lay explanations for poverty in Turkey and their determinants. The Journal of Social Psychology, 137(6), 728-738. DOI: 10.1080/00224549709595494

Muñoz, M; Vázquez, C; Bermejo, M., \& Vázquez, J.J. (1999). Stressful life events among homeless people: Quantity, types, timing and perceived causality. Journal of Community Psychology, 27 (1), 73-87.

Niemelä, M. (2008). Perceptions of the causes of poverty in Finland. Acta Sociologica, 51(1), 23-40. DOI: $10.1177 / 0001699307086816$

Nisbet, R. E. \& Ross, L. (1980). Human Inference: Strategies and Shortcomings of Social Judgment. Englewood Cliffs, NJ: Prentice Hall.

Oorschot, W. van \& Halman, L. (2000). Blame or fate, individual or social? An international comparison of popular explanations of poverty. European Societies, 2(1), 1-28.

Panadero, S. \& Vázquez, J.J. (2008). Perceived causes of poverty in developing nations: Causes of Third World Poverty Questionnaire in Spanish-speaking samples. Social Behavior and Personality, 36(4), 571-576. DOI: http://dx.doi.org/10.2224/sbp.2008.36.4.571

Peressini, T. (2007). Perceived reasons for homelessness in Canada: Testing the heterogeneity hypothesis. Canadian Journal of Urban Research, 16(1), 112-126.

Plujá i Calderon, M. (2011). Con techo y sin hogar. Efectos de la vivienda precaria en la vida de las personas de Barcelona. Madrid: Caritas Española Editores

Reutter, L.I., Harrison, M.J., \& Neufeld, A. (2002). Public support for poverty-related policies. Canadian Journal of Public Health, 93(4), 297-302.

Reutter, L.I., Veenstra, G., Stewart, M.J., Raphael, D., Love, R., Makwarimba, E. \& McMurray, S. (2006). Public Attributions for Poverty in Canada. The Canadian Review of Sociology and Anthropology, 43(1), 1-22. DOI: 10.1111/j.1755-618X.2006.tb00852.x

Shaver, K.G. (1970). Defensive attribution: Effects of severity and relevance on the responsibility assigned for an accident. Journal of Personality and Social Psychology, 14(2), 101.

Shirazi, R. \& Biel, A. (2005). Internal-external causal attributions and perceived government responsibility for need provision. Journal of Cross-Cultural Psychology, 36(1), 96-116. DOI: $10.1177 / 0022022104271428$.

Tessler, R., Rosenheck, R. \& Gamache, G. (2001). Gender differences in self-reported reasons for homelessness. Journal of Social Distress and the Homeless, 10 (3), 243-254.

Toro, P.A., Tompsett, C.J., Lombardo, S., Philippot, P., Nachtergael, H., Galand, B., Schlienz, N., Stammel, N., Yabar, Y., Blume, M., MacKay, L. \& Harvey, K. (2007). Homelessness in Europe and the United States: A Comparison of Prevalence and Public Opinion. Journal of Social Issues, 63, 505-524. DOI: 10.1111/j.1540-4560.2007.00521.x

Vázquez, J.J. \& Panadero, S. (2007). Ideología, acción política y atribuciones causales de la pobreza en los estados menos desarrollados. Psicología Política, 35, 35-51.

Vázquez, J.J. \& Panadero, S. (2009). Poverty in less developed countries: Analysis of attributional differences between Central-Americans undergraduates. Interamerican Journal of Psychology, 43(2), 297-308.

Vázquez, J.J. (2013). Happiness among the garbage. Differences in overall happiness among trash pickers in León (Nicaragua). Journal of Positive Psychology, 8(1), 1-11. DOI: 10.1080/17439760.2012.743574. 
Vázquez, J.J., Panadero, S., Martín, R.M., \& Díaz-Pescador, V. (2015). Access to new information and communication technologies among homeless people in Madrid (Spain). Journal of Community Psychology, 43(3), 338-347. DOI: 10.1002/jcop.21682

Weiner, B. \& Graham, S. (1989). Understandig the motivational rol of affect: Life-span research from attributional perspective. Cognition and Emotion, 3 (4), 401-419.

Weiner, B. (1986). An Attributional Theory of Achievement Motivation and Emotion. Nueva York: Springer-Verlag.

Weiner, B., Osborne, D., \& Rudolph, U. (2011). An attributional analysis of reactions to poverty: the political ideology of the giver and the perceived morality of the receiver. Personality and Social Psychology Review, 15(2), 199-213. DOI: $10.1177 / 1088868310387615$.

Wollie, C.W. (2009). Causal attributions for poverty among youths in Bahir Dar, Amhara region, Ethiopia. Journal of Social, Evolutionary, and Cultural Psychology, 3(3), 251272. DOI: $10.1037 / \mathrm{h} 0099319$.

Zucker, G.S., \& Weiner, B. (1993). Conservatism and perceptions of poverty: An attributional analysis. Journal of Applied Social Psychology, 23(12), 925-943. DOI: 10.1111/j.15591816.1993.tb01014.x 